\title{
CONFERENCE ON IN SITU COMPOSITES
}

The fourth Conference on In Situ Composites attracted thirty contributed and invited papers, in which were examined and discussed new findings and technologically significant developments emerging from studies of directionally transformed materials. A fewer number of papers were presented, compared with previous conferences, on the high temperature structural eutectic alloys for gas turbine applications. The eutectic superalloys, NiTac-14B and $\gamma / \gamma^{\prime}+\mathrm{Cr}_{3} \mathrm{C}_{2}, \quad$ are currently undergoing turbine blade/vane casting trials after extensive mechanical property evaluations and will be engine tested during 1982 and 1983. Significant progress in achieving improved transverse ductility in NiTac-14B and scale up to complex shapes through commercial casting houses were reported by GECR\&D and NPL respectively.

The growth, coarsening and complex stress distribution existing between fibers and lamellae in aligned eutectics were examined using in situ transmission electron microscopy by French researchers at Grenoble. Changes in lamellar spacing, fault nucleation and coarsening in a thermal gradient were graphically captured in movies taken off the 1 $\mathrm{MeV}$ electron microscope.

Progress on non-structural applications of in situ composites continues with the integrated circuit construction and further sophistication of field emitters by Georgia Tech researchers with emphasis on increases in current density and life of the arrays. Fault free eutectic thin-films $(\sim 200 \AA)$ thick were produced at GECR\&D using evaporated layers on glass slides and laser heat sources. An exciting novel technique to produce in situ composites by mechanical means from cast dendritic structures was described by Verhoeven and Bevk. Research under these professors at Iowa State and Harvard University produced $\mathrm{Cu}-\mathrm{Nb}+\mathrm{Sn}$ filamentary composites by wire drawing techniques with varying volume fractions which had outstanding superconducting properties. In composites with the smallest filaments $(d \sim 50-200 \AA)$ and filament densities as high as $10^{10} / \mathrm{cm}^{2}$, the dislocation density in the matrix reaches values of $10^{13} \mathrm{~cm} / \mathrm{cm}^{3}$. The yield stress of these samples increases dramatically over the predictions based on the "rule of mixtures" and their ultimate tensile strength approaches the estimated theoretical strength of the material $(\sim 2.7 \mathrm{GPa})$.

Discussions on the chocolatevanilla phase diagram (below) continued over lunch and dinner with variations in bubble diagrams in beer.

\section{Malcolm McLean}

National Physical Laboratory England

F. D. Lemkey

United Technologies

Research Center

H. E. Cline

General Electric

Research and Development

Chairmen

\section{The Chocolate-Vanilla Phase Diagram}

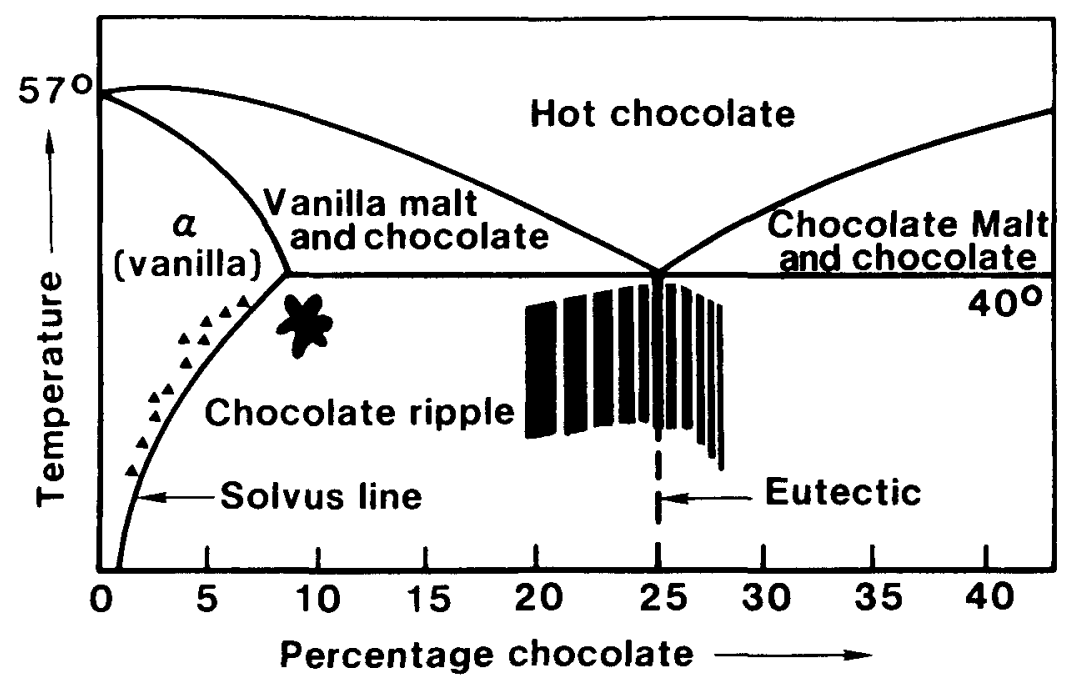

